\title{
Trust, Covenant, and Responsibility
}

Some of the most illuminating recent philosophical analyses of trust begin with its "primitive», spontaneous forms - with, for example, the dependence of children on their elders. In these contexts, a certain passive receptivity is fundamental: young children are not yet in a position to evaluate their parents, or to doubt what they are told. The development of these critical capacities - of the ability to distrust others - comes later, as a result, largely, of life's disappointments. Lars Hertzberg puts the point this way:

«Believing what others say is a refinement of other, more basic forms of trust. Only in a context constituted by trust, we might say, do truth and the making of statements have a place. We must begin by trying to understand the nature of trust as a primitive reaction.»

Hertzberg accordingly distinguishes trust - which is not based on evidential grounds, and which involves a kind of primordial openness to others - from what he calls reliance - which requires the exercise of one's own judgment about others.

Yet, beginning with the primitive reactions of children can present philosophical problems of its own. The opposite of trust is ordinarily said to be distrust (or something similar: mistrust, suspicion, doubt, disbelief, etc.), whereas an infant that did not respond in characteristic dependence on its parents would be cut off from development altogether, incapable of the exercise of reason required for distrust. Because it requires a different contrast case, the dependence of children on their parents does not seem to provide us with a good model for thinking about more mature forms of trust, such as can be said to grow over time between adults. Though some of these mature forms are arguably survivals from an earlier, more generalized attitude of openness, others are of a kind that cannot meaningfully be predicated of young children.

Here I propose to take as my point of departure one of these more developed forms of trust - namely, the trust characteristic of covenantal relationships. It is my claim not that this is the only, or even the most important, form of trust, or that it provides a paradigm for thinking

L. Hertzberg, On the Attitude of Trust, Inquiry 31 (3), 1988, 309. 
about trust in general, but that in its particularity it sheds a unique light on a range of other phenomena, illuminating from a new angle some of the issues Hertzberg raises. I conclude with some reflections concerning the relation between trust and responsibility.

Consider, then, a marriage between two people, $A$ and $B$. For the sake of the discussion, let us imagine that $A$ and $B$ did not meet until they were already adults, competent in the ways of both trust and distrust. Their relationship developed slowly, as each gradually yielded to the other, but now - it may be imagined - they care deeply for one another, and, if asked, would each say that the other is his or her most trusted companion.

Unlike the forms of "primitive trust» at the center of Hertzberg's discussion, the relationship between $A$ and $B$ developed over time, and its progress - assuming that it was indeed typical - was at times hesitant and halting. Each had to learn to trust the other; or, to put it the other way around, each had to earn - and perhaps at times to win back - the other's trust. But unlike in the case of what Hertzberg calls «reliability», the mutual giving of trust we have imagined is not a matter of each coming to regard the other as competent, or reliable, or useful in the pursuit of goals specifiable independently of the relationship. Indeed, we can imagine that for each, the other is in some ways an impediment to the realization of at least some of these goals. Because each cares about the good of the other, each is of course desirous to please the other, and to be of assistance when the other is in need, but precisely this same concern with the other's wellbeing requires each to distinguish when appropriate between what the other (thinks he or she) wants and what would be good for the other, all things considered.

We can perhaps throw further light on Hertzberg's distinction between trust and reliance by relating it here to another important difference - that between covenant and contract. A contract - for purposes of jurisprudence, usually defined as a legally binding agreement - is a pact for mutual advantage, and it is ordinarily possible to say, in advance, how each party hopes to benefit. It is entered into with clearly defined goals in mind and motivated by the expectation that the other is prepared to meet specified terms - e.g., to provide some service in exchange for a consideration. The other is instrumental to the realization of one's goals but externally related to them: that is, the goals are intelligible independently of the contract itself, and while one may require another's help in achieving them, these goals can be articulated without reference to anyone in particular. Before entering a contract, one is, so to speak, free to shop around. 
The special legal obligations between parties to a contract are thus brought into being through the contract itself: a contract creates rights and responsibilities. Nevertheless, one's identity is not fundamentally altered by virtue of having entered into a contract. This is connected with the fact that contractual relationships are ordinarily temporary, easily dissolved when the terms of the contract have been fulfilled. Indeed, from a legal perspective, one important function of contracts is to limit liability: a contract places restrictions on what each party can legitimately demand from the other. Contracts can be amended, but one's responsibilities under a contract do not ordinarily grow or evolve over time; they are not open-ended. Contracts are properly conceived as valid only when the parties involved have freely consented to the terms. It is, consequently, crucial to the idea of contracting that each party is conceived as autonomous and fully rational (in a means-ends sense). Enforceable contracts cannot be entered into under duress, when one is intoxicated, or by someone who is mentally incompetent or under age, for instance.

Covenanting, though in outward appearances similar to contracting, operates according to an importantly different logic. Whereas a contract is entered into in pursuit of goals independent of the contract itself, a covenant is not in this sense purely instrumental: it is, one could say, an end in itself, rather than simply a means. Here the identity of the parties is fundamentally altered by virtue of the covenantal relationship: one becomes, for example, a husband, a citizen, a chosen people. In a contractual relationship, one reserves one's autonomy, whereas in a covenantal relationship, one casts one's lot in with another, giving oneself to the other in trust. Moreover, covenanting is inherently mutual; each party undertakes responsibility for the other.

A covenant alters the way in which its parties are related to one another, but it does not ordinarily create a relationship where none previously existed, as is typical in the case of contracts. This is partly because covenanting requires trust, and this often has to be built up gradually over time. Moreover, unlike contracts, covenants are open-ended - a feature reflected, for example, when the parties to a marriage vow to take one another «for better or worse, in sickness or in health, till death do us part.» Whereas the terms of a contract determine the relationship between the parties to it, in a covenant it is the relationship that determines the "terms», and these cannot ordinarily be specified in advance. Nevertheless, covenanting involves volition, as can be seen from the example of marriage vows: the parties to a covenant must consent to be bound together in this open-ended way. In this respect, a marriage covenant, for example, is importantly dif- 
ferent from the relationship between an infant and its mother, which is not a matter of will or choice.

The difference between contracts and covenants can helpfully be illustrated in terms of certain features of Hertzberg's distinction between reliance and trust: whereas contractual relationships are based on reliance, covenantal relationships are based on trust. Before signing a contract, a smart businessperson, for example, is careful to consider the available evidence as to the other party's ability to make good on what is promised. In this weighing of probabilities, the other person's character is relevant only in a limited sense: one need not like or admire the person with whom one enters into a contract. What matters is whether, in respect to the limited range of conditions specified by the contract, he or she can be relied upon. In a covenant, by contrast, what matters is not the other's ability to deliver on any particular promise, but that the other cares about one's wellbeing. To enter into a covenant is to surrender oneself to the other in trust. This trust involves risk, but it is not a probability judgment.

However, an examination of covenantal relationships can also shed light on certain underdeveloped features of Hertzberg's account. Whereas most of Hertzberg's examples of trust involve hierarchical or asymmetrical relationships, such as those of children to parents, novices to masters, etc., the example of covenanting shows that what is important is not asymmetry (e.g., of knowledge, skills, experience, status), but heteronomy: to trust another is to entrust oneself to the other. Because the giving of trust can be reciprocated, relationships based on trust can be characterized by equality and mutuality. In a covenantal relationship, for example, each cares about the other's wellbeing, and entrusts her wellbeing to the care of the other. In the process, the identities of both parties are transformed.

Insofar as it requires a reference to the good - i.e., to one's objective wellbeing, rather than simply one's subjective desires or goals - the trust involved in covenantal relationships necessarily involves a moral dimension. In this respect, it differs from reliance, though the nature of this difference requires careful elucidation. For starters, consider the following remarks by Hertzberg concerning the allocation of responsibility in the case of disappointments:

If I was wrong in relying on someone, this was a failure in my judgment: it would have been better had I been more astute. When someone's trust has been misplaced, however, it is always, I want to say, a misunderstanding to regard this as a shortcoming on his part. The responsibility rests with the person who failed the trust. The reason for this is that, unlike reliance, the grammar 
of trust involves a perspective of justice: trust can only concern that which one person can rightfully demand of another. So if I claim that $A$ trusts $B$ to do $X$, I commit myself to thinking that (in the absence of exonerating circumstances) $B$ is open to blame if he fails to do it. If on the other hand I think it would be wrong for $B$ to do $X$, or if I do not agree that $A$ can demand it, then I will not think about $A$ 's expectation as a case of trust, even if that were the way in which $A$ represents it to himself. ${ }^{2}$

Here the moral distinction between reliance and trust is rather sharply drawn, but is it drawn in the right place?

Let's begin with the claim that if one relies wrongly on another, the blame lies with oneself. This may be true in certain circumstances, but it is not difficult to imagine cases in which a person could be entirely justified (given the evidence available to her) in relying on others who, in the event, let her down. One can also easily imagine cases in which a person is forced to rely on others, who may not fully measure up to her ideals. ${ }^{3}$ In such cases - though perhaps not only in these - those relied upon arguably bear some, if not all, of the moral responsibility when things go wrong. I have suggested that reliance is central to the practice of contracting, but from a legal perspective, responsibility for breach of contract always falls on the unreliable party. Indeed, "unreliable» is largely a term of reproach.

Conversely, Hertzberg's claim that a person can never be faulted for having misplaced her trust does not seem to follow from the argument he offers on its behalf. To be sure, if $A$ can «rightfully demand» that $B$ do $X$, and $B$ fails to do do it, then $B$ is blameworthy. But it does not follow from the fact that $B$ is blameworthy for having failed to do $X$ that $A$ bears no responsibility for having expected $B$ to do it. There is, after all, no contradiction in recognizing both that $\mathrm{B}$ has an obligation to do $X$ and that he or she is unlikely to do it.

In speaking of «expectations» and of "what one person can rightfully demand from another», Hertzberg here seems to be employing a vocabulary more commonly used in connection with reliance. An infant, to use one of Hertzberg's own examples, does not (in the relevant sense) «expect» its parents «to do $X$ », and while it is indeed unthinkable that we should blame the infant for its parents' neglect, the nature of the parents' responsibility for the infant's wellbeing is not helpfully framed in terms of what the infant can «rightfully demand» of them. Part of the reason we would not think to hold an

\footnotetext{
2 Ibid., 319-320.

3 Though perhaps it could be argued that in cases of this latter kind one ought to proportion one's expectations to the evidence of others' reliability.
} 
infant responsible for having «misplaced its trust» is that it has absolutely no choice in the matter. It has not exercised poor judgment, if only because it has not exercised judgment at all.

The source of this confusion may lie in an overly abstract conception of responsibility. Hertzberg speaks alternately of failures of judgment and moral failures: both are - or at any rate can be-blameworthy, but the nature of the failure differs, and one can be innocent in one respect while being guilty in the other. Consider a breach of contract in which $B$ is the unreliable party. Here the legal (and arguably moral) blame lies entirely with $B$, and yet, under appropriate conditions, $A$ can be faulted for having entered into the contract in the first place. (Of course, contracting is a special case of reliance, and there are others in which one person can let another person down - i.e., prove "unreliable» from the other person's perspective - without incurring legal or moral blame.) $A$, it may be said, acted imprudently: he or she ought to have been more circumspect. If, by contrast, Hertzberg is right, and trust is not based on prudential considerations - on an analysis of probabilities - then there can be no corresponding «failure of judgment» when it is violated.

But why is the untrustworthy party necessarily blameworthy? Hertzberg suggests that it is because he or she has violated a legitimate moral demand - i.e., the demand to do $X$. But that cannot be the whole of the story, since if $B$ had failed to do $X$ for $A$, and $X$ represented a legitimate demand (something $B$ owed to $A$ ), then $B$ could be faulted irrespective of whether or not $A$ had trusted $B$. In other words, Hertzberg's explanation of why it is blameworthy for $B$ to have violated $A$ 's trust ironically leaves the trust itself out of the picture, focusing instead on the content of $A$ 's expectation. By contrast, I would like to suggest that the wrongdoing consists (also) in $B$ 's indifference to the good of A, with which $A$ had entrusted $B$. Here the nature of the obligation cannot be articulated fully without reference to the trust itself, because in a sense the trust creates the obligation. By entrusting oneself to the other, one places him or her under an obligation. This is a legitimate obligation, not simply a subjective preference or expectation, because it necessarily involves a reference to $A$ 's good, conceived objectively. To be the object of trust is thus to bear responsibility for another. This, I submit, is what is meant by calling a breach of trust a «betrayal». What is violated is not an abstract principle, but a person.

Does it follow from all of this, however, that one who trusts wrongly can never be faulted? I think not. In criticizing Hertzberg's preoccupation with "primitive» trust, I noted earlier that, among 
adults, the opposite of trust is ordinarily said to be distrust, whereas young children have not yet developed the critical capacities required for distrust. But if distrust involves the operation of critical capacities, then the failure to bring these capacities to bear, when appropriate, can presumably be blameworthy. To be sure, trust does not involve the kind of means-ends reasoning characteristic of reliance. A marriage covenant, for example, is not entered into in pursuit of goals that can be articulated entirely independently. Yet, covenanting does involve consent, and it is predicated on the expectation that the other party cares about one's good. This expectation is not easily verifiable, but it can, under certain circumstances, be falsified - although, unlike in the case of reliance it is not always easy to say precisely what would count decisively against it - and in these cases, I suggest, trust can be unwarranted.

- Dr. Richard Amesbury ist Associate Professor of Ethics an der Claremont Schoo of Theology in Kalifornien. Im Frühjahrsemester 2010 weilte er im Rahmen des Austauschs mit der Claremont Graduate University am Institut für Hermeneutik und Religionsphilosophie. 